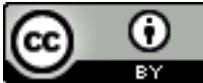

\title{
A PEDAGOGIA UNIVERSITÁRIA E A FORMAÇÃo INICIAL DO PEDAGOGO EM TRÊS LAGOAS - MS: RESULTADOS LOCAIS DA POLÍTICA BRASILEIRA DE EXPANSÃO DO ENSINO SUPERIOR
}

\author{
THE UNIVERSITY PEDAGOGY AND INITIAL PEDAGOGY TRAINING \\ IN TRÊS LAGOAS - MS: LOCAL RESULTS FROM THE BRAZILIAN \\ POLICY WITH THE EXPANSION OF HIGHER EDUCATION \\ UNA PEDAGOGÍA UNIVERSITARIA Y LA FORMACIÓN PEDAGOGA \\ INICIAL EN TRES LAGOS - MS: RESULTADOS DE DESARROLLO LOCAL \\ DE LAS POLÍTICA BRASILEÑA DE EDUCACIÓN SUPERIOR
}

\section{Paulo Fioravante Giareta ${ }^{1}$ Valdeci Luiz Fontoura dos Santos ${ }^{2}$ Janaína Montagner ${ }^{3}$ Maria da Pena Santos de Souza Wilma Massimino}

\begin{abstract}
RESUMO
O artigo retrata a caracterização político-pedagógica assumida no âmbito da política de expansão da educação superior no Brasil, para a formação de professores. A investigação se apoia na análise da oferta do Curso de Pedagogia, do município de Três Lagoas, região Leste do Estado de Mato Grosso do Sul. Enquanto resultado preliminar de uma pesquisa maior e institucional, vinculada à Universidade Federal de Mato Grosso do Sul UFMS, responde pelo objetivo de apontar a configuração da política de formação de professores, por meio da expansão e interiorização da oferta da educação superior em licenciatura. Metodologicamente, a pesquisa se fundamenta na análise documental, para a organização, leitura e interpretação dos dados apoiada na técnica da análise de conteúdo. Os dados foram levantados com suporte nas bases oficiais - MEC, INEP e site das IES pesquisadas, tendo por recorte temporal a oferta registrada no ano de $2015 \mathrm{e}$, a análise se estruturou a partir de categorias como tipologia institucional, modalidade institucional, modalidade jurídico-administrativa das instituições e período de oferta. A pesquisa aponta para a caracterização da expansão e interiorização da educação superior para a formação de professores, especialmente, para a formação em pedagogia, fundamentada nas matrizes de redução de custos, que no contexto pesquisado, responde por forte vinculação da oferta via instituições privadas, centrada na pedagogia do ensino e com predomínio da oferta na modalidade à distância.
\end{abstract}

PALAVRAS-CHAVE: Educação superior. Pedagogia universitária. Formação de professores.

\section{ABSTRACT}

The article portraies with the political and pedagogical characterization undertaken in the context of higher education expansion policy in Brazil, for the training of teachers, based on the analysis of the offer of the Education Course. The research brings the analysis of the offer of the course in the context of the Três Lagoas city, Eastern region of Mato Grosso do Sul state. While preliminary results of a larger, institutional research, linked to the Federal University of Mato Grosso do Sul -. UFMS, accounts for the purpose of pointing out the

\footnotetext{
${ }^{1}$ Doutorado em Educação pela UFPR; mestrado em Educação pela FURB. Professor da Universidade Federal de Mato Grosso do Sul. E-mail: pfgiareta27@yahoo.com.br

${ }^{2}$ Graduado em Pedagogia pelas Faculdades Integradas Rui Barbosa - FIRB (Andradina - SP), especialista em Educação pela Universidade Federal de Mato Grosso do Sul; mestre em Educação pela Universidade Estadual Paulista. Professor Assistente da Universidade Federal de Mato Grosso do Sul.

${ }^{3}$ Mestra em Educação pela Universidade Federal de Mato Grosso do Sul (UFMS) Docente pela Universidade Federal de Mato Grosso do Sul UFMS/CPTL em Três Lagoas.
}

Submetido em: 10/08/2016 - Aceito em: 23/09/2016.

\begin{tabular}{l|l|l|l|l|l|l} 
(C) Rev. Inter. Educ. Sup. & Campinas, SP & v.2 & n.2 & p.311-327 & maio/ago. 2016 & ISSN 2446-9424
\end{tabular}


configuration of teacher training policy through expansion and internalization of higher education in degree mode. Methodologically, the research structure from the document analysis, which for organization, reading and interpretation of the data brought in the technique of content analysis. The data were collected from official bases - MEC, INEP and site of the HEIs surveyed -, with the time frame the offer recorded in 2015 and the analysis was structured from categories such as institutional type, institutional mode, juridical mode administrative institutions and offer period. The research points to the characterize the expansion and internalization of higher education for the training of teachers, especially for training in pedagogy, from cost reduction matrices, which in the context researched accounts for strong binding supply via private institutions centered pedagogy of teaching and predominantly supply in the distance.

KEYWORDS: College education. University pedagogy. Teacher training.

\section{RESUMEN}

El artículo se ocupa de la caracterización política y pedagógica llevada a cabo en el contexto de la política de expansión de la educación superior en Brasil, para la formación de maestros, basado en el análisis de la oferta del Curso de Educación. La investigación aporta el análisis de la oferta del curso en el contexto de la ciudad de Três Lagoas, Estado de la región oriental de Mato Grosso do Sul, Si bien los resultados preliminares de una investigación más amplia, institucionales, vinculados a la Universidad Federal de Mato Grosso do Sul -. UFMS, cuentas con el fin de señalar la configuración de la política de formación docente a través de la expansión y la internalización de la oferta de la educación superior en el modo carrera. Metodológicamente, la estructura de investigación a partir del análisis de documentos, que para la organización, la lectura y la interpretación de los datos se lleva la técnica de análisis de contenido. Los datos se obtuvieron de las bases oficiales - MEC, INEP y el sitio de las IES encuestadas -, con el marco de tiempo de la oferta registrada en 2015 y el análisis se estructura a partir de categorías tales como tipo institucional, de modo institucional, el modo jurídica instituciones administrativas y período de la oferta. Los puntos de investigación para caracterizar la expansión e internalización de la educación superior para la formación de profesores, sobre todo para la formación en la pedagogía, a partir de matrices de reducción de costes, que en el contexto investigado las cuentas para el suministro de unión fuerte a través de instituciones privadas pedagogía centrada en la enseñanza y en su mayor parte de suministro en la distancia.

PALABRAS- CLAVE: Educación universitaria. Pedagogía universitaria. Formación de profesores.

\section{INTRODUÇÃO}

Este trabalho socializa resultados preliminares de uma pesquisa institucional ${ }^{4}$, e objetiva analisar a configuração da política de privatização da formação de professores, por meio da expansão e interiorização da oferta da educação superior no Brasil na modalidade licenciatura.

Parte-se do reconhecimento de que a referida privatização, mediante a política de expansão, impacta sobre a própria política de oferta educacional, que, no âmbito da expansão da Educação Superior, a presente pesquisa assume como objeto de investigação. Propõe-se, assim, elucidar e indicar os impactos e configurações assumidos para a política de formação de professores pela análise da oferta de cursos de Pedagogia.

\footnotetext{
${ }^{4}$ Projeto denominado de Pedagogia Universitária para Formação de Pedagogos e a Qualidade da Educação Básica, vinculado a Universidade Federal de Mato Grosso do Sul - UFMS e aportado junto ao Grupo de Pesquisa Laboratório Multidisciplinar de Ensino e Aprendizagem - LEA. Cadastrado no CNPq e certificado pela UFMS.
}

\begin{tabular}{l|l|l|l|l|l|l} 
(c) Rev. Inter. Educ. Sup. & Campinas, SP & v.2 & n.2 & p.311-327 & maio/ago. 2016 & ISSN 2446-9424 \\
\hline
\end{tabular}


Elege-se como lócus, para o desenvolvimento da pesquisa, o município de Três Lagoas, localizado na região Leste do estado do Mato Grosso do Sul, mais especificamente na região administrativa denominada de bolsão sul-mato-grossense. $\mathrm{O}$ município teve, na última década, seu desenvolvimento acelerado por meio da chegada do complexo de produção de celulose alterando, assim, sua caracterização de pequeno município, baseado na agropecuária, para um perfil industrial, concebido pelo poder local com uma política de desenvolvimento econômico e social expansionista. ${ }^{5}$

Segundo os dados do site do IBGE de 2015 tal processo de industrialização elevou a estatística populacional do Município de 84.650 habitantes em 2004 para 113.619 em 2015, alcançando-o ao terceiro lugar na economia do Estado de Mato Grosso do Sul.

Neste cenário, foca-se na política brasileira de expansão da oferta da formação de professores tendo como hipótese que em Três Lagoas também existe reflexos de tal expansão por meio da presença de instituições privadas de ensino superior. Para tanto, o levantamento dos dados está fundamentado, metodologicamente, na técnica da análise documental, que para organização, leitura e interpretação dos dados se apropria da técnica de análise de conteúdo.

Nesta primeira etapa da pesquisa os dados foram levantados por meio das bases oficiais - MEC (Ministério da Educação), INEP (Instituto Nacional de Estudos e Pesquisas Educacionais Anísio Teixeira) e site das IES (Instituições de Ensino Superior) pesquisadas com recorte temporal no ano de 2015, referentes à Três Lagoas (MS). Assim, o anunciado estudo se estrutura com base em quatro categorias analíticas: tipologia institucional, que diz da tipificação institucional da oferta como universidade, centro universitário e faculdade; modalidade institucional, que responde pela caracterização da modalidade de oferta dos cursos como presencial, semipresencial e a distância; modalidade jurídico-administrativa, enquanto configuração da natureza da oferta, tais como pública ou privada; e, período de oferta, que diz do período diário indicado pelas instituições para contato/encontro formativo com os estudantes como matutino, vespertino, noturno, agendado.

\footnotetext{
${ }^{5}$ Notamos ainda que a história do desenvolvimento socioeconômico da cidade, como destaca Terezinha Viegas (2007), pode ser marcada por saltos de desenvolvimento, sendo o primeiro a partir da chegada da antiga Estrada de Ferro Noroeste do Brasil (NOB), com a sua obra em 1909, que resultou em grande desenvolvimento populacional. O segundo fato se constitui pela construção da barragem de Jupiá e da usina hidroelétrica Engenheiro Souza Dias em 1960 que também implicou em um crescimento considerável. E, por fim, temos o atual contexto, sobretudo a partir 2007 com a chegada do complexo de fábrica direcionado aos setores de papel e de celulose. (Cf. FIGUEIREDO et al, 2009).
}

\begin{tabular}{l|l|l|l|l|l|l} 
(C) Rev. Inter. Educ. Sup. & Campinas, SP & v.2 & n.2 & p.311-327 & maio/ago. 2016 & ISSN 2446-9424 \\
\hline
\end{tabular}




\section{CONSIDERAÇÕES HISTÓRICAS}

A análise sobre o início da oferta de Educação Superior no Brasil remete ao período colonial, à época, organizada administrativa e metodologicamente pela Companhia de Jesus ${ }^{6}$ - Jesuítas - respectivamente, a partir das suas estruturas escolares e do método centrado na Ratio Studiorum. Proposta educativa marcadamente elitista ${ }^{7}$ e comportamental, traços também incorporados como política de estado no contexto do período imperial, representado pelo deslocamento da Corte para a colônia em 1808.

A expectativa gerada em torno da transferência da sede do poder metropolitano para o Brasil, no âmbito da política educacional, especialmente, para a Educação Superior, não se efetiva para além do aprofundamento do seu, já indicado, caráter elitista e de uma vinculação ideológica ao atendimento de demandas burocráticas do Estado, enquanto escolas superiores do império (CUNHA, 2007). Proposta que caracterizará a estruturação da Educação Superior no Brasil a partir de estabelecimentos isolados e centrados no princípio técnicoprofissionalizante (RIBEIRO, 2007) tendo como elemento estruturante o modelo francêsnapoleônico não universitário, voltado para a formação de quadros para a estrutura burocrática do Brasil de então (PIMENTA; ANASTASIOU, 2002).

A escola de primeiras letras ${ }^{8}$, no contexto imperial, não figura politicamente relevante, e foi caracterizada como inexistente a própria preocupação com a formação dos licenciados, cabendo aos bacharéis o exercício da docência (PROTA, 1987). É possível afirmar da efetiva inexistência de política estatal de formação de professores, fragmentada, a partir de 1831, na criação das primeiras escolas normais, em caráter secundário, tendo sua expressão máxima na escola normal oficial criada em 1881. Destaque-se que as escolas normais, gênese no Brasil da formação de professores para o que estamos convencionando denominar educação da infância (educação infantil e anos iniciais do ensino fundamental), foram objeto de legislação

\footnotetext{
${ }^{6}$ A educação jesuítica, em certo sentido, inaugura a educação brasileira no início do século XVI, que se manteve vinculada ao mundo Europeu, já que a colonização brasileira perpassa do resultado da expansão comercial da burguesia enricada com a revolução, assim as colônias valiam pelos produtos que forneciam tendo como estrutura econômica o modelo "agrário-exportador dependente", nesse sentido a educação não era o objetivo prioritário, sendo que para funções nos campos não era exigido formação. (ARANHA, 2006. p.139). Desta forma quando os filhos dos colonos terminavam sua aprendizagem na escola de primeiras letras (ler e escrever) partiam ou para estudar teologia, formando-se como padre e mestre para manter viva a obra jesuíta, ou então, preparavam-se para acender ao ensino superior na Europa, notadamente em Coimbra em Portugal e Montpellier na França.

${ }^{7} \mathrm{O}$ que se tinha era uma visão etnocêntrica motivada a partir da proposta educativa europeia que figura como modelo a ser seguido, implicando em acentuado desprezo pela cultura popular (indígena e negra) marginalizada no processo de homogeneização.

${ }^{8}$ As Escolas e/ou aulas públicas de primeiras letras foram regulamentadas, no âmbito da capital, em 1827 por ato real visando o ensino da leitura, da escrita, das quatro operações de aritmética contando também com a prática de quebrados, decimais e proporções, além das noções mais gerais de geometria prática, a gramática de língua nacional. Era, também, espaço para o ensino dos princípios de moral cristã e da doutrina da religião católica apostólica romana e tinha, legalmente, como indicação para as leituras a serem feitas pelas crianças, a Constituição do Império e a História do Brasil. Seus professores eram selecionados entre os "interessados" que eram submetidos a exames públicos e não se exigia nenhuma formação específica.
}

\begin{tabular}{l|l|l|l|l|l|l|}
\hline (C) Rev. Inter. Educ. Sup. & Campinas, SP & v.2 & n.2 & p.311-327 & maio/ago. 2016 & ISSN 2446-9424
\end{tabular}


específica com vistas a atender a necessidade de professores e professoras para o ensino de primeiras letras vindo efetivamente a serem criadas, pelas províncias, em 1934, efeito da reforma constitucional daquele mesmo ano (Cf. TANURI, 2000).

A hipervalorização social conferida à elitista Educação Superior imperial protagoniza processos de expansão controlada, quer pelo estabelecimento de critérios seletivos para acesso ou pela própria resistência à abertura para a pedagogia universitária. A Universidade no Brasil ilustra como feito da década de 1920, já no contexto republicano, com as marcas políticas e epistemológicas do modelo de educação vigente até então. Estas marcas se caracterizam, tanto pela manutenção da função técnica da pedagogia universitária, quanto pela estruturação das universidades via política de aglutinação de faculdades isoladas, fenômeno bem representado pelo Decreto 14.343 de 1920 e pela Lei 1.254 de 1950 que, respectivamente, cria oficialmente a primeira universidade brasileira - Universidade do Rio de Janeiro, enquanto resultado da aglutinação de três escolas tradicionais (Escola Politécnica, Escola de Medicina e uma das Escolas de Direito) e federaliza, novamente, por meio do princípio da aglutinação, os estabelecimentos de ensino superior mantidos pelos estados, pelos municípios e por particulares.

Esse posicionamento político-administrativo e pedagógico tem especial efeito sobre a política de formação de professores, que responde por grande dificuldade em figurar, agora, a partir da pedagogia universitária. O próprio Curso de pedagogia criado pelo Decreto 1.190 de 1939 se destina, inicialmente, à formação de bacharéis para atuar como técnicos de educação, quando licenciados, respondiam como docentes nos cursos normais 9 .

A Lei 5.540 de 1968 que responde como a lei de reforma da Educação Superior no contexto da política do estado militarizado, mais do que uma política de expansão da oferta de Educação Superior para o propagado desenvolvimentismo econômico e industrial, estruturou-se como uma política pedagogicamente conservadora, administrativamente disciplinadora e fiscalizatória em nome da modernização, que para a política de formação de professores se aporta no fomento a uma formação aligeirada com cursos de curta duração; complementada pela adoção e ampliação da política do material didático; centrada na formação técnica complementada por algumas poucas disciplinas pedagógicas; e comumente vinculada a instituições isoladas assentadas na oferta privada (CUNHA; GÓES, 2002; FÁVERO, 1991).

\footnotetext{
${ }^{9}$ O Curso de Pedagogia, apenas recentemente (DCN 2006) passou a formar, obrigatoriamente, o pedagogo docente para a educação da infância. Tal organização atual do curso é fruto de imbricado debate sobre a identidade do pedagogo, que inicialmente só era admitido como docente no magistério das então chamadas disciplinas pedagógicas/matérias pedagógicas do Curso Normal. Entretanto, a partir dos pareceres de Walnir Chagas, membro do Conselho Federal de Educação (terminologia da época) (LIBANEO; PIMENTA ,1999), criou-se o debate entre o "maior" e "menor". Tal postulação coloca, assim, que se o pedagogo docente poderia assumir o magistério das matérias pedagógicas/disciplinas pedagógicas no curso normal por qual razão não poderia fazer o "menor" sendo também docente nas séries iniciais?
}

\begin{tabular}{l|l|l|l|l|l|l} 
(C) Rev. Inter. Educ. Sup. & Campinas, SP & v.2 & n.2 & p.311-327 & maio/ago. 2016 & ISSN 2446-9424
\end{tabular} 
Vale a indicação de Chauí (1990) que identifica nestas proposições, embora se justifique a partir de princípios como educação, desenvolvimento e modernização, a acomodação prática da política educacional aos novos arranjos produtivos, demarcados por movimentos como formação aligeirada de profissionais para as demandas tecnológicas avançadas; profissionalização rápida e privatizada como condição para a geração de mão de obra especializada; e um acentuado viés profissionalizante da educação.

Esta proposta técnico-profissionalizante, privatista e pedagogicamente fragmentada, adentra as décadas de 1970 e 1990, fundamentada em políticas de formação de professores, com base nas matrizes de recuperação de custos, com visível redução dos gastos públicos com a educação e reforço do setor privado.

Tais teses afetam a própria Carta Magna de 1988, tanto pela manutenção da liberdade de oferta pela iniciativa privada (Art. 209), quanto pela possibilidade de repasse de recursos públicos para as instituições privadas (Art. 213) e a Lei de Diretrizes e Bases - LDB de 1996, que além de reconhecer e normatizar a natureza pública e privada das instituições de ensino superior, também as reconhece como uma instituição de diferentes e variados graus de abrangência (Art. 45), incorporando, ainda, no seu artigo 62 a formação de professores a partir de institutos superiores de educação e admitindo, também, como "formação mínima para o exercício do magistério na educação infantil e nas quatro primeiras séries do ensino fundamental, a ofertada em nível médio, na modalidade normal".

Os dados do Censo da Educação Superior, disponibilizados pelo INEP, considerando o início da década de 1990 até o ano da promulgação a LDB - 1996, indicam que na prática esta política precipita uma expansão vegetativa da oferta de educação superior e fomenta a iniciativa privada, inclusive, com redução das IES públicas, fato denota um processo de privatização por meio da expansão do ensino superior na iniciativa privada. Observar os dados da TABELA 1.

TABELA 1. IES por Categoria Administrativa - Brasil 1991 - 1996

\begin{tabular}{cccc}
\hline Ano & Total & Pública & Privadas \\
\hline $\mathbf{1 9 9 1}$ & 893 & 222 & 671 \\
$\mathbf{1 9 9 2}$ & 893 & 227 & 666 \\
$\mathbf{1 9 9 3}$ & 873 & 227 & 652 \\
$\mathbf{1 9 9 4}$ & 851 & 218 & 633 \\
$\mathbf{1 9 9 5}$ & 894 & 210 & 684 \\
$\mathbf{1 9 9 6}$ & 922 & 211 & 711 \\
\hline
\end{tabular}

Fonte: Censo da Educação Superior INEP - Modificado pelos autores (2016) 
Pode-se inferir que tais dados apontam para uma forte tendência de expansão da oferta do ensino superior na iniciativa privada, no período do governo FHC, que acomoda as discussões e consequente promulgação da LDB de 1996. Entre os anos de 1991 e 1996 o número de IES públicas diminui enquanto o de IES privadas salta de 671 para 711. Entretanto, convém destacar que esta é uma tendência que fora inaugurada, no Brasil, no âmbito da reforma do ensino superior em 1968, pois, pensando as matrículas no ensino superior,

entre 1965 e 1980, as matrículas do setor privado saltaram de 142 mil para 885 mil alunos, passando de $44 \%$ do total das matrículas para $64 \%$ nesse período. Em sua fase inicial, ou seja, desde o final dos anos de 1960 até a década de 1970, a expansão do setor privado laico ocorreu basicamente através da proliferação de estabelecimentos isolados de pequeno porte (MARTINS, 2009, p.23).

A busca pela análise sobre a política de formação de professores pós Lei 9394/96, demanda o destaque, imediato, de que os indicativos acima apontados tendem a se asseverar, caracterizando seu progressivo e contínuo deslocamento para uma pedagogia não universitária e vinculada ao empreendimento privado.

\section{O CONTEXTO LEgal E A REFORMA dA FORMAÇÃo DE PROFESSORES APÓS A LDB 9394/96}

A promulgação da Carta Magna da redemocratização brasileira de 1988, consequentemente, a regulamentação da política educacional pela LDB de 1996, salvaguardando, em ambos os documentos, a natureza e finalidade da educação como direito e de responsabilidade do Estado, é perceptível a incidência e incorporação dos traços reformistas, que na prática não rompe, mas aprofunda a anunciada política de recuperação de custos.

Esta política, assumida pela própria LDB de 1996, assegura ainda mais, conforme já indicado anteriormente, a política privatizante e fragmentada para a oferta de educação superior, especialmente para a formação de professores, que na década de 1990, se vê radicalmente afetada por "reformas pontuais", para usar uma expressão de Sguissardi (2009), derivada do disciplinamento da própria LDB, e materializada por Decretos e Portarias tais como: Decretos n. 2.207/1997, 2.306/1997 e 3.860/2001 e Portarias 637, 638, 639, 640 e 641, todas de 1997. Aparato legal que, respectivamente, reafirma o princípio público e privado da oferta de ensino superior; sua progressiva estratificação institucional com variados graus de abrangência ou especialização; a aposta na diversificação institucional configurando novas formas de organização acadêmica: universidades, centros universitário, faculdades integradas, faculdades, institutos e escolas superiores; bem como, promove a abertura para a oferta de ensino superior a distância; e oficializa a implementação de sistemas de avaliação institucional. 
A Lei n 010172 de 09 de janeiro de 2001, que diz do Plano Nacional de Educação PNE 2001 a 2011, de forma articulada e coerente as deliberações da LDB de 1996 e do citado aparato legal, reafirma o aludido posicionamento político, no âmbito educação superior, tanto reconhecendo a importância da iniciativa privada que já detinha aproximadamente $70 \%$ das vagas ofertadas, a exaustiva apologia e normatização da política de avaliação institucional nos diferentes níveis e modalidades de oferta educacional, a expansão de vagas via oferta noturna e pela promoção da oferta pela via da diversificação institucional, quanto pelo incentivo e orientação pela adoção do ensino a distância. O PNE chega a dedicar um item (item 6) exclusivamente para normatizar a política de formação desta modalidade de ensino, especialmente orientada para a formação de professores conforme preconiza a meta 11 do item 6 "iniciar, logo após a aprovação do Plano, a oferta de cursos a distância, em nível superior, especialmente na área de formação de professores para a educação básica”.

A manutenção e fomento desta matriz promove uma expansão da Educação Superior, especialmente para a formação de professores, assentada em projetos e programas pontuais, tais como os centrados em concessão de crédito para financiamento da formação em instituições de ensino superior privadas, Lei 10.260 de 12 de julho de 2001 que dispõe sobre o Fundo de Financiamento ao estudante do Ensino Superior - FIES; concessão de bolsas integrais ou parciais para ocupação de vagas em instituições privadas mediante isenção fiscal, Lei 11.096 de 13 de janeiro de 2005 que institui o Programa Universidade para Todos PROUNI; implementação de programa temporário de transferência de recurso mediante contrato de reestruturação das universidades, Decreto 6.096 de 24 de abril de 2007 que institui o Programa de Apoio a Planos de Reestruturação e Expansão das Universidades Federais - REUNI; bem como o investimento em um sistema de universidade virtual para a oferta prioritária de cursos de licenciatura na modalidade de educação a distância, Decreto 5.800 de 8 de junho de 2006 que dispõe sobre o Sistema de Universidade Aberta do Brasil $\mathrm{UAB}$.

A análise dos dados do Censo de Educação Superior, correspondente à primeira década do ano 2000, período politicamente disciplinado pela LDB de 1996 e pelo Plano Nacional de Educação - PNE 2001 a 2011, mostra que na prática se efetivou uma expressiva expansão da Educação Superior, contudo, fundamentalmente assentada no fomento a iniciativa privada, sabendo que a mesma privilegia o investimento em instituições isoladas. Confere TABELA 2.

TABELA 2. IES por Categoria Administrativa - Brasil 2000 - 2010

\begin{tabular}{cccc}
\hline Ano & Total & Públicas & Privadas \\
\hline $\mathbf{2 0 0 0}$ & 1.180 & 176 & 1.004 \\
$\mathbf{2 0 0 1}$ & 1.391 & 183 & 1.208
\end{tabular}

v.2

n. 2




\begin{tabular}{llll}
\hline $\mathbf{2 0 0 2}$ & 1.637 & 195 & 1.442 \\
$\mathbf{2 0 0 3}$ & 1.859 & 207 & 1.652 \\
$\mathbf{2 0 0 4}$ & 2.013 & 224 & 1.789 \\
$\mathbf{2 0 0 5}$ & 2.165 & 231 & 1.934 \\
$\mathbf{2 0 0 6}$ & 2.270 & 248 & 2.032 \\
$\mathbf{2 0 0 7}$ & 2.281 & 249 & 2.032 \\
$\mathbf{2 0 0 8}$ & 2.252 & 236 & 2.016 \\
$\mathbf{2 0 0 9}$ & 2.314 & 245 & 2.068 \\
$\mathbf{2 0 1 0}$ & 2.378 & 278 & 2.100 \\
\hline
\end{tabular}

Fonte: Censo da Educação Superior INEP - Modificado pelos autores (2016)

Essa mesma configuração pode ser percebida quando analisamos os dados referentes às matrículas presenciais no referido período. Confere TABELA 3.

TABELA 3. Matrículas presenciais em IESs - BRASIL 2000 - 2010

\begin{tabular}{cccc}
\hline Ano & Total & Públicas & Privadas \\
\hline $\mathbf{2 0 0 0}$ & 2.694 .245 & 887.026 & 1.807 .219 \\
$\mathbf{2 0 0 1}$ & 3.030 .754 & 939.225 & 2.091 .529 \\
$\mathbf{2 0 0 2}$ & 3.479 .913 & 1.051 .655 & 2.428 .258 \\
$\mathbf{2 0 0 3}$ & 3.887 .022 & 1.136 .370 & 2.750 .652 \\
$\mathbf{2 0 0 4}$ & 4.163 .733 & 1.178 .328 & 2.985 .405 \\
$\mathbf{2 0 0 5}$ & 4.453 .156 & 1.192 .189 & 3.260 .967 \\
$\mathbf{2 0 0 6}$ & 4.676 .646 & 1.209 .304 & 3.467 .342 \\
$\mathbf{2 0 0 7}$ & 4.880 .381 & 1.240 .968 & 3.639 .413 \\
$\mathbf{2 0 0 8}$ & 5.080 .056 & 1.273 .965 & 3.639 .413 \\
$\mathbf{2 0 0 9}$ & 5.115 .896 & 1.351 .168 & 3.764 .728 \\
$\mathbf{2 0 1 0}$ & 5.449 .120 & 1.461 .696 & 3.987 .424 \\
\hline
\end{tabular}

Fonte: Censo de Educação Superior INEP - Modificado pelos autores (2016)

Convém destacar, ainda, conforme estudo de Gatti, Barretto e André (2011) que vinculado às políticas de fomento à iniciativa privada de ensino, o PNE 2001 - 2011, na prática, acaba por articular a política de formação inicial de professores no Brasil à rede privada de ensino e à modalidade a distância, chegando em 2009 com 50\% dos cursos de licenciatura nesta modalidade.

A Lei 13.005, de 25 de junho de 2014, ainda que com praticamente três anos de atraso, estabeleceu o novo Plano Nacional de Educação, indicando a manutenção da matriz 
política para a Educação Superior, consequentemente, também para a política de formação de professores, bem traduzida pela meta 12 em sua estratégia 12. 20 "ampliar, no âmbito do Fundo de Financiamento ao Estudante do Ensino Superior - FIES, e que trata a Lei $n^{\circ}$ 10.260, de 12 de julho de 2001, e do Programa Universidade para Todos - PROUNI, de que trata a Lei $\mathrm{n}^{\mathrm{o}} 11.096$, de 13 de janeiro de 2005 [...]", que para pesquisadores como Gatti, Barretto e André (2011) intensifica o deslocamento político e pedagógico da formação universitária para as instituições isoladas vinculadas à iniciativa privada. Quando acomodada a partir da Pedagogia Universitária, figura vinculada à oferta na modalidade à distância, que no caso específico do curso de Pedagogia no Brasil, no contexto temporal da presente pesquisa, já responde por aproximadamente $80 \%$ da oferta.

Convém destacar, ainda, que a análise dos resultados locais da política de formação de professores, espelhada pela oferta do Curso de Pedagogia, apresenta-se, de forma coerente, filiada e fortemente caracterizada pelos indicadores e disciplinamento político pedagógico acima elucidado.

\section{O CURSO DE PEDAGOGIA NO MUNICÍPIO DE TRÊS LAGOAS NO ESTADO DE MATO GROSSO DO SUL}

A literatura sobre a formação do pedagogo no centro-oeste brasileiro não é farta como em outras regiões do país e, no caso específico de Três Lagoas, encontrar estes estudos nos periódicos nacionais que registram a produção da pesquisa em educação figura como tarefa difícil. É mediado por estas condições de pesquisa e produção de conhecimento que se procedeu ao levantamento feito e organizado pelo projeto de pesquisa 'Pedagogia Universitária’ para Formação de Pedagogo e a Qualidade da Educação Básica.

O levantamento realizado no segundo semestre de 2015 evidencia com clareza a proposta que prevalece na política de formação de pedagogo. A pesquisa, conforme já indicado no texto, construída por meio da análise de bases de dados oficiais - MEC, INEP e site das IES - identifica a atuação de 9 Instituições de Ensino Superior com oferta do curso no município de Três Lagoas, mesclando oferta pública e privada, na modalidade presencial e a distância, aportada na diversificação institucional a partir de faculdades ${ }^{10}$, centro universitários e universidade, também, com oferta nos período noturno, diurno e horários agendados.

\footnotetext{
${ }^{10}$ Não obstante o disciplinamento legal das IES, no contexto da legislação educacional brasileira, que prevê uma distinção entre Faculdades Integradas e/ou Isoladas, a presente pesquisa, tendo como foco a pedagogia de formação de professores considera inexpressiva, metodologicamente, a referida distinção, uma vez que ambas tem como exigência legal uma pedagogia centrada, meramente, no ensino, sem exigências quanto a extensão e a pesquisa. Assim, usa-se, aqui, a categoria Faculdade indicando tanto as Faculdades Integradas quanto as Isoladas.
}

\begin{tabular}{l|l|l|l|l|l|l}
\hline (C) Rev. Inter. Educ. Sup. & Campinas, SP & v.2 & n.2 & p.311-327 & maio/ago. 2016 & ISSN 2446-9424
\end{tabular} 
A organização dos dados com base nas categorias já indicadas no texto: tipologia institucional, modalidade institucional, modalidade jurídico-administrativa e período de oferta ajudam na compreensão do referido disciplinamento.

A análise a partir da categoria Tipologia Institucional, que diz do modo de organização institucional e da forma de incidência acadêmica, mostra que das 9 Instituições de Ensino Superior (IES) que ofertam o curso de Pedagogia, 45\% encontram-se credenciadas junto ao MEC como Universidades, destas apenas 1 é pública. Confere GRÁFICO 1:

\section{Tipologia Institucional - Três Lagoas}

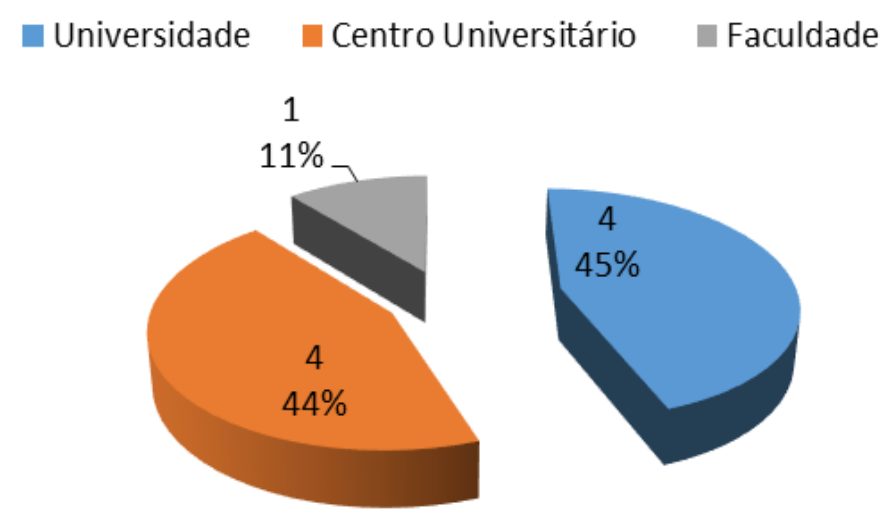

GRÁFICO 1. Oferta de Curso de Pedagogia por Tipologia Institucional (2015) Fonte: Organizado pelo Grupo de Pesquisa (2016)

Este dado bem caracteriza a opção político pedagógica de fundamento na diversificação institucional na política de expansão de oferta de cursos/vagas para formação de pedagogos ${ }^{11}$. Para Scheibe e Aguiar (1999) a proposta de diversificação institucional, com forte incidência sobre a própria diversificação pedagógica para formação de professores, diz de um movimento político intencional, otimizado por meio do caráter generalista e flexível da nova LDB e aprofundado no período pós-LDB, a partir de reformas pontuais.

Segundo as autoras citadas, a reboque da criação de ineditismos tipológicos para educação superior, que a partir do Decreto 2.306 de 1997 além de regulamentar a existência de IES públicas e privadas passa a identificar a existência de IES privadas sem e com fins

\footnotetext{
${ }^{11}$ Opção que tanto caracterizou governos de agenda marcadamente neoliberal como de FHC, quanto o governo denominado de frente popular como o de Lula, mesmo que este último tenha retomado, timidamente, a expansão do ensino superior público via criação de Universidades e Institutos Federais que obrigatoriamente devem ofertar $25 \%$ de seus cursos na modalidade licenciatura. Os dados apontam que não há alteração de agenda
} político pedagógica quanto a proposta de formação de professores nos Cursos de Pedagogia.

\begin{tabular}{l|l|l|l|l|l} 
(C) Rev. Inter. Educ. Sup. & Campinas, SP & v.2 & n.2 & p.311-327 & maio/ago. 2016
\end{tabular} 
lucrativos, pulveriza-se a organização acadêmica reconhecendo a educação superior no sistema federal de ensino desde sua expressão universitária até a modalidade de formação técnica pós-média.

\begin{abstract}
Instaurou-se com essa legislação a distinção entre universidades de pesquisa e universidades de ensino e normatizou-se uma hierarquia no interior do ensino superior que, certamente, demandará cada vez mais em reivindicações diferenciadas para cada setor. Destaque-se aí a questão da formação de professores. Estabeleceuse como locus privilegiado para essa formação o nível mais baixo da hierarquia. Um caminho que, independentemente do setor ao qual se vincula (público, particular, comunitário), deverá ser o menos oneroso. (SCHEIBE; AGUIAR, 1999, p. 222).
\end{abstract}

Essa diversificação, com especial incidência sobre a política e pedagogia para formação de pedagogos, é percebida, também, quando analisamos as modalidades de oferta, aqui, denominadas de Modalidade Institucional, uma vez que esta oferta se apresenta bem diversificada, quer presencial, à distância ou semipresencial.

A análise da categoria Modalidade Institucional ao mesmo tempo em que demonstra o apego pela diversificação da oferta indica, também, uma aguda polarização, uma vez que $67 \%$ desta oferta é disponibilizada na modalidade à distância, sendo $22 \%$ na presencial e $11 \%$ na semipresencial. Correspondendo, em números absolutos, por 6 instituições centradas na oferta à distância, 2 presencial e 1 na semipresencial. Confere GRÁFICO 2.

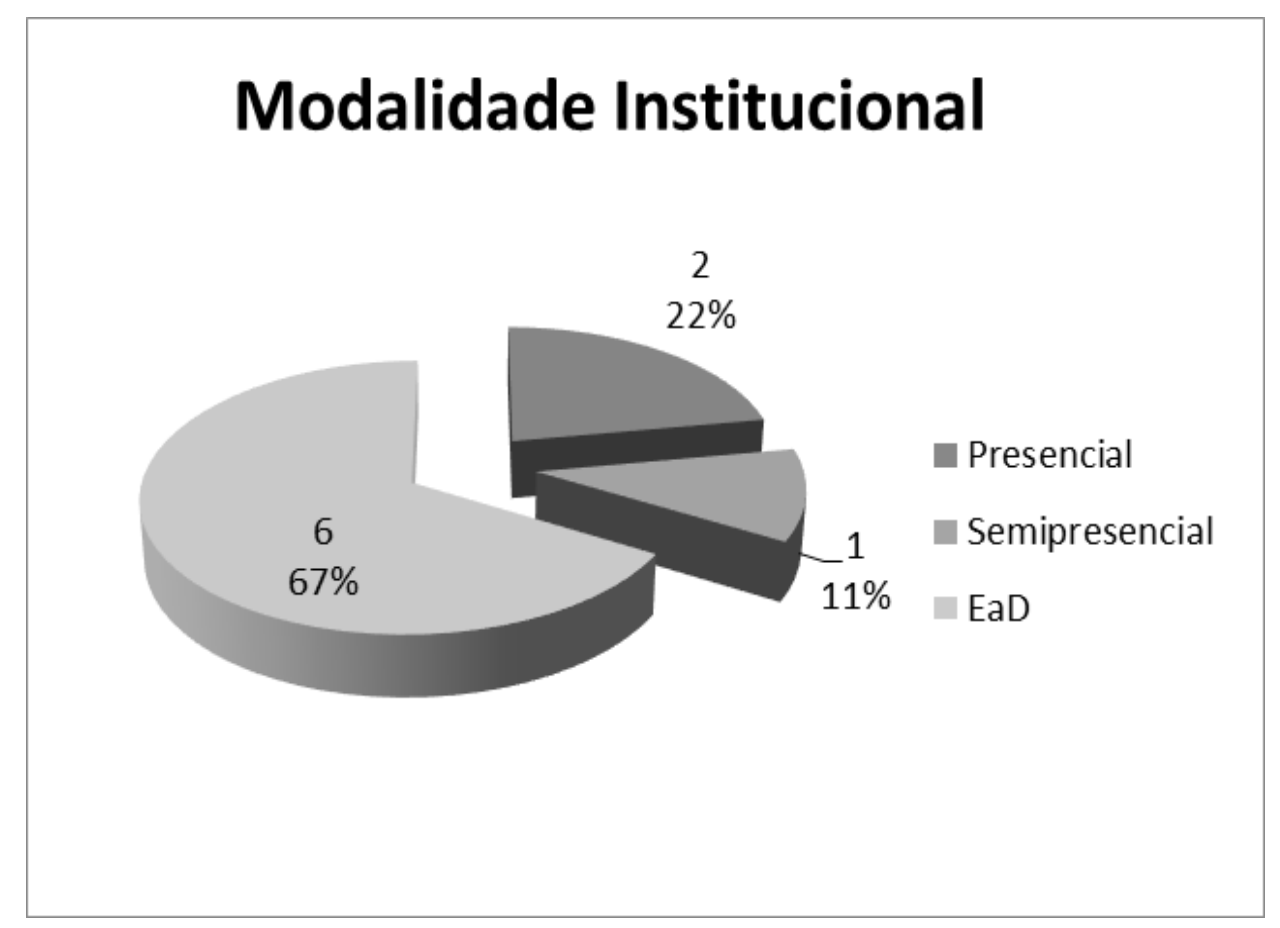

GRÁFICO 2. Oferta do Curso de Pedagogia por Modalidade Institucional (2015)

Fonte: Organizado pelo Grupo de Pesquisa (2016) 
Pesquisas como as de Giolo (2008) e Gatti, Barretto e André (2011) demonstram que a LDB ao sugerir a educação à distância a compreende, inicialmente, como iniciativa pública ou próxima dela, conforme disciplina seu art. 80, que no âmbito da política de formação de professores estaria assentada no objetivo de promover formação regular e continuada aos professores em exercício. Os autores demonstram este fato quando apontam que dados de 2001 indicam que 100\% das matrículas em cursos de Pedagogia e Normal Superior à distância estão em instituições públicas.

Esta iniciativa se desloca, progressivamente, legalmente amparada no sistema educacional brasileiro - Lei n 010172 de 2001, Decreto n 5.622/2005, Decreto n 6.303 de 2007 -, para a iniciativa privada que em 2006 já acomodaria 76,4\% das matrículas dos cursos de Pedagogia e Normal Superior. Dados que bem representam a expressão local indicada pelo GRÁFICO 2.

A referida polarização e diversificação acadêmico-institucional se evidenciam ainda mais, quando analisamos os dados a partir da categoria Modalidade Jurídico-Administrativa, que trata da natureza pública ou privada das instituições que ofertam o curso de Pedagogia no Município. Esta categoria indica que expressivamente $89 \%$ da oferta se dá via instituições privadas e apenas $11 \%$ em instituições públicas. Respectivamente, 8 instituições com oferta privada e 1 com oferta pública. Confere GRÁFICO 3:

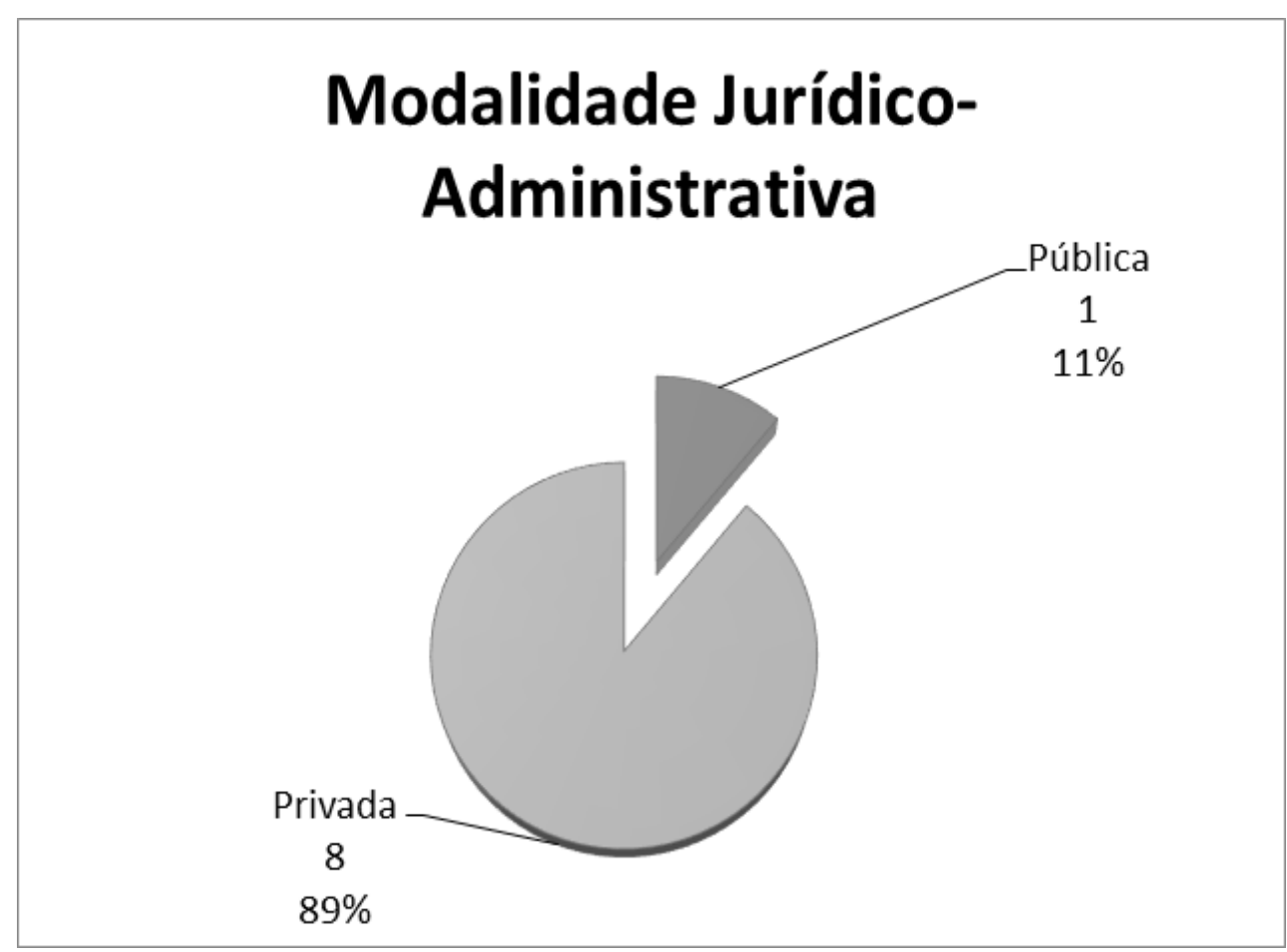

GRÁFICO 3. Oferta do Curso de Pedagogia por Modalidade Jurídico-Administrativa (2015)

Fonte: Organizado pelo Grupo de Pesquisa (2016) 
Os dados possibilitam a leitura de que no contexto local, fiel ao disciplinamento macro do sistema educacional brasileiro, a aposta na política de expansão da educação superior acomodada em dispositivos legais como diversificação, tanto institucional quanto acadêmica, na prática, articula e legítima a expansão privada (SGUISSARDI, 2009), com forte incidência sobre a política de formação de professores.

A aposta na política de expansão privada e na modalidade a distância aponta para o próprio desafio de garantir a formação dos pedagogos a partir da pedagogia universitária, enquanto formação centrada no ensino, pesquisa e extensão. Os dados aqui analisados, referente ao município de Três Lagoas, confirmam a indicação já apontada por Scheibe e Aguiar (1999) que no contexto desta política fica estabelecido como espaço privilegiado para esta formação uma pedagogia, ainda que universitária, centrada no ensino, prevalecendo, mais que o compromisso com uma proposta qualificada de formação, a preocupação com uma política de redução de custos.

Ainda, colaboram com esta constatação os dados apontados pela categoria Período de Oferta uma vez que indica pela prevalência da oferta em horários agendados - $67 \%$ da oferta ou noturno - $100 \%$ da oferta -, enquanto oferta de ensino, preferencialmente, em trânsito e atrativamente adequada ao tempo do estudante trabalhador. Organização de horário e modalidade de oferta a partir da análise de demandas de mercado.

\section{CONSIDERAÇÕES FINAIS}

A pesquisa aponta para a dificuldade histórica do sistema educacional brasileiro em acomodar a formação de professores, destacadamente, a formação de pedagogos, no âmbito da pedagogia universitária. Esta dificuldade, inicialmente, está representada pela vinculação da formação de professores para a educação primária nos denominados Cursos Normais, deslocados do contexto da formação superior, que no período pós-LDB de 1996 passa a ser regulamentada por uma forte política de diversificação institucional e acadêmica.

Os dados analisados com base na oferta de Cursos de Pedagogia no município de Três Lagoas (MS) demonstra a incidência deste alinhamento político-pedagógico a partir da política de expansão e interiorização da educação superior. Alinhamento que aprofunda a proposta de formação de professores apoiada nas matrizes de redução de custo, materializada no fomento da oferta via instituições privadas, com absoluta predominância da modalidade à distância e no escopo da diversificação institucional, politicamente, vinculada à pedagogia do ensino.

Destaca-se que estas considerações e apontamentos passam a demandar o aprofundamento das pesquisas, não apenas pelo viés da regulamentação da expansão da oferta, mas da própria possibilidade de incidência sobre a política de expansão a partir de 
indicadores que caracterizem a preocupação com a qualidade científico-cultural da formação dos pedagogos. Objeto que direciona o olhar para a pedagogia universitária viabilizada para a formação do pedagogo e o compromisso político e epistemológico para com a qualidade da Educação Básica.

\section{REFERÊNCIAS}

BRASIL. Constituição de (1988). Constituição da República Federativa do Brasil. Brasília. Senado Federal, 1998.

BRASIL. Lei $\mathbf{n}^{\mathbf{0}}$ 10.260, de 12 de julho de 2001. Dispõe sobre o Fundo de Financiamento ao estudante do Ensino Superior e dá outras providências. Brasília, 2001f. Disponível em: 〈http://www.planalto.gov.br>. Acesso em janeiro de 2016.

BRASIL. Lei $\mathbf{n}^{\circ}$ 11.096, de 13 de janeiro de 2005. Institui o Programa Universidade para Todos - PROUNI, regulação a atuação de entidades beneficente de assistência social no ensino superior; altera a Lei $n^{\circ} 10.891$, de 9 de julho de 2004, e dá outras providências. Brasília 2005. Disponível em: 〈http://www.planalto.gov.br〉 . Acesso em janeiro de 2016.

BRASIL. Lei no 010.172, de 09 de janeiro de 2001. Aprova o Plano Nacional de Educação e dá outras providências. Brasília 2001. Disponível em:

$<$ http://portal.mec.gov.br/arquivos/pdf/L10172.pdf $>$.Acesso em janeiro de 2016.

BRASIL. Lei no 13.005, de 25 de junho de 2014. Aprova o Plano Nacional de Educação PNE e dá outras providências. Brasília 2014. Disponível em: <http://www.planalto.gov.br/ccivil_03/_ato2011-2014/2014/lei/113005.htm>. Acesso em janeiro de 2016.

BRASIL. Lei no 1.254, de 04 de dezembro de 1.950. Dispõe sobre o sistema federal de ensino superior. Disponível em: <http://www.planalto.gov.br/ccivil_03/leis/1950-

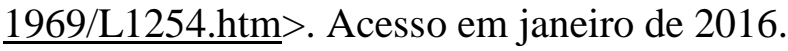

BRASIL. Lei $\mathbf{n}^{0}$ 5.540, de 28 de novembro de 1.968. Fixa normas de organização e funcionamento do ensino superior e sua articulação com a escola média, e dá outras providências. Disponível em: <http://presrepublica.jusbrasil.com.br/legislacao/109783/lei5540-68>. Acesso em janeiro de 2016.

BRASIL. Decreto $\mathbf{n}^{\mathbf{0}}$ 2.207, de 15 de abril de 1997. Regulamenta, para o Sistema Federal de Ensino, as disposições contidas nos arts. 19, 20, 45, 46 e $\S 1^{\circ}, 52$, parágrafo único, 54 e 88 da Lei $\mathrm{n}^{\circ}$ 9.394, de 20 de dezembro de 1996, e dá outras providências. Brasília 1997. Disponível em: 〈http://www.planalto.gov.br>. Acesso em janeiro de 2016.

BRASIL. Decreto no 2.306, de 19 de agosto de 1997. Regulamenta, para o Sistema Fedral de Ensino, as disposições contidas no art. 10 da Medida Provisória n 1.477-39 de 8 de agosto de 1997 , e nos arts. $16,19,20,45,46$ e $§ 1^{\circ}, 52$, parágrafo único, 54 e 88 da Lei ${ }^{\circ} 9.394$, de 
20 de dezembro de 1996, e dá outras providências. Brasília, 1997a. Disponível em: <http://www.planalto.gov.br $>$. Acesso em janeiro de 2016.

BRASIL. Decreto n⿳ 3.860, de 9 de julho de 2001. Dispõe sobre a organização do ensino superior, a avaliação de cursos e instituições, e dá outras providências. Brasília, 2001e. Disponível em: 〈http://www.planalto.gov.br〉. Acesso em janeiro de 2016.

BRASIL. Decreto $\mathbf{n}^{0}$ 5.800, de 08 de junho de 2006. Dispõe sobre o Sistema Universidade Aberta do Brasil - UAB. Brasília, 2006. Disponível em : <http://www.planalto.gov.br/ccivil_03/_ato2004-2006/2006/decreto/d5800.htm $>$. Acesso em janeiro de 2016.

BRASIL. Decreto $\mathbf{n}^{\circ}$ 14.343, de 7 de setembro de 1920. Institui a Universidade do Rio de Janeiro. Disponível em: http://www2.camara.leg.br/legin/fed/decret/1920-1929/decreto14343-7-setembro-1920-570508-publicacaooriginal-93654-pe.html Acesso em janeiro de 2016.

BRASIL. Decreto no 6.096, de 24 de abril de 2007. Institui o Programa de Apoio a Planos de Reestruturação e Expansão das Universidades Federais - REUNI. Brasília 2007.

Disponível em: 〈http://www.planalto.gov.br>. Acesso em janeiro de 2016.

Decreto no 1.190, de 04 de abril de 1939. Dá organização à Faculdade Nacional de Filosofia. Disponível em: <http://www.planalto.gov.br/ccivil_03/decreto-lei/1937-

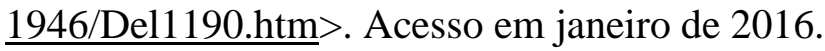

BRASIL. Ministério da Educação. Lei no 9.394/1996. Diretrizes e Bases da Educação Nacional. Brasília, 1996.

BRASIL. Ministério da Educação. Portaria nº 637/1997. Dispõe sobre o credenciamento de Universidades, Brasília, 1997b.

BRASIL. Ministério da Educação. Portaria n 639/1997. Dispõe sobre o credenciamento de centros universitários, para o sistema federal de ensino superior, Brasília, 1997c.

BRASIL. Ministério da Educação. Portaria nº 640/1997. Dispõe sobre o credenciamento de faculdades integradas, faculdades, institutos superiores ou escolas superiores, Brasília, 1997d.

BRASIL. Ministério da Educação. Portaria no 641/1997. Dispõe sobre a autorização de novos cursos em faculdades integradas, faculdades, institutos superiores ou escolas superiores em funcionamento, Brasília, 1997e.

CHAUI, Marilene. A Lei 5692, Ciências Humanas e o Ensino Profissionalizante. In.: PILETTI, Nelson.; PILETTI, Claudinei. História da Educaçãa. São Paulo: Editora Ática, 1990.

CUNHA, Luiz Antônio. A universidade temporã: o ensino superior, da Colônia à Era Vargas. 3 ed. São Paulo: Editora Unisep, 2007. 
CUNHA, Luiz Antônio; GÓES de Moacyr. O golpe na educação. Rio de Janeiro: Jorge Zahar, 2002.

FAVERO, Maria de Lurdes de Albuquerque. A Da universidade "modernizada" à universidade disciplinada: Atcon e Meira Mattos. São Paulo: Cortez: Autores Associados, 1991.

FIGUEIREDO, Amanda Aparecida Costa at al. A chegada da fábrica: expectativas e qualificação dos trabalhadores. In: SIMPÓSIO SOBRE TRABALHO E EDUCAÇÃO NETE, 5, 2009. Belo Horizonte. Anais... Belo Horizonte: UFMG, v. 1. p. 1-23, 2009.

GATTI, Bernardete Angelina; BARRETTO, Elba Siqueira de Sá; ANDRÉ, Marli Eliza Dalmozo de Afonso. Política Docente no Brasil: um estado da arte. Brasília: UNESCO, 2011.

GIOLO, Jaime. A Educação a Distância e a Formação de Professores. Educ. Soc., Campinas, vol. 29, n. 105, p. 1211-1234, set./dez. 2008.

LIBANEO, José Carlos. e PIMENTA, Selma Garrido. Formação de profissionais da educação: visão crítica e perspectiva de mudança. Educ. Soc., Campinas, v. 20, n. 68, p. 239277, dez. 1999.

MARTINS, Carlos Benedito. A reforma universitária de 1968 e a abertura para o ensino superior privado no Brasil. Educ. Soc., Campinas, vol. 30, n. 106, p. 15-35, jan./abr. 2009.

OLIVEIRA, Dalila Andrade. A gestão democrática da educação no contexto da reforma do Estado. In: FERREIRA, Naura Syria Carapeto (Org.). Gestão da educação: impasses, perspectivas e compromissos. São Paulo: Cortez Editora, 2006. p. 91-112.

PIMENTA, Selma. Garrido; ANASTAISOU, Lea das Graças Camargo. Docência no ensino superior. São Paulo: Cortez, 2002.

PROTA, Leonardo. Um novo modelo de universidade. São Paulo: Convívio, 1987.

RIBEIRO, Maria Luisa Santos. História da Educação Brasileira. Campinas: Autores Associados, 2007.

SCHEIBE, Leda; AGUIAR, Márcia Angela. Formação de Profissionais da Educação no Brasil: o curso de pedagogia em questão. Educação \& Sociedade, ano XX, n.68, p. 220-238, dezembro/99.

SGUISSARDI, Valdemar. Universidade Brasileira no Século XXI: desafios do presente. São Paulo: Cortez, 2009.

TANURI, Leonor Maria. História da formação de professores. Rev. Bras. Educ., Rio de Janeiro, n. 14, p. 61-88, ago. 2000. 